\title{
Ludwig's angina and ketoacidosis as a first manifestation of diabetes mellitus
}

\author{
Pedro Infante-Cossío ${ }^{1}$, Esteban Fernández-Hinojosa ${ }^{2}$, Miguel-Ángel Mangas-Cruz ${ }^{3}$, Luis-Miguel González- \\ Pérez ${ }^{4}$
}

\author{
${ }^{1}$ Profesor Titular Vinculado, Servicio de Cirugía Oral y Maxilofacial, Hospital Universitario Virgen del Rocío, Universidad de \\ Sevilla \\ ${ }^{2}$ Facultativo Especialista del Servicio de Cuidados Críticos y Urgencias, Hospital Universitario Virgen del Rocío, Sevilla \\ ${ }^{3}$ Facultativo Especialista del Servicio de Endocrinología, Hospital Universitario Virgen del Rocío, Sevilla \\ ${ }^{4}$ Facultativo Especialista del Servicio de Cirugía Oral y Maxilofacial, Hospital Universitario Virgen del Rocío, Sevilla
}

Correspondence:

Servicio de Cirugía Oral y Maxilofacial

Hospital Universitario Virgen del Rocio

Av. Manuel Siurot

41013-Sevilla, Spain

pinfante@us.es

\author{
Infante-Cossío P, Fernández-Hinojosa E, Mangas-Cruz MA, González- \\ Pérez LM. Ludwig's angina and ketoacidosis as a first manifestation of dia- \\ betes mellitus. Med Oral Patol Oral Cir Bucal. 2010 Jul 1;15 (4):e624-7. \\ http://www.medicinaoral.com/medoralfree 01/v15i3/medoralv15i3p624.pdf

\begin{abstract}
Ludwig's angina is a serious and rapidly progressive infectious process that spreads through the floor of the mouth and neck. In this paper we present an infrequent case of a patient who suffered an odontogenic infection with poor response to the previous treatment, which evolved towards a Ludwig's angina combined with ketoacidosis in the context of a diabetes mellitus not known before. According to the literature reviewed, this case report represents the first contribution of a Ludwig's angina and ketoacidosis as an initial manifestation of a diabetes mellitus. The airway management, the antibiotic prescription and the surgical drainage allowed the healing of the patient without medical complications. Factors of co-morbidity like the diabetes mellitus together with focus tooth of infection may eventually turn into serious medical complications as the diabetic ketoacidosis and develop potentially lethal cervical infections.
\end{abstract}

Key words: Ludwig's angina, odontogenic infection, diabetes mellitus, diabetic ketoacidosis.

\section{Introduction}

Ludwig's angina is a serious and rapidly progressive infectious process that spreads by the floor of the mouth affecting simultaneously to submandibular, sublingual and submental spaces. The infection generally begins as cellulites, then it turns into fasciitis, and finally, into real abscess that results in a woody and hard swelling of the floor of the mouth and suprahioid region in a bilateral form, with displacement of the tongue and airway affectation. It was described for the first time in 1836 by
Willhelm Frederick von Ludwig as a gangrenous induration of soft tissues of the neck and the floor of mouth (1). Without a treatment it was frequently fatal, since the imminent risk of asphyxia was added to the seriousness derived from the infectious clinical symptoms, positioning the rate of mortality on $50 \%$. The aggressive surgical intervention, the antibiotic introduction and the improvement of the odontological cares have determined a significant reduction of the mortality rate 
to less than $10 \%$ (2). Nevertheless, at present, this process still represents a therapeutic challenge due to the potentially serious complications that it can cause.

Although Ludwig's angina is a very slightly frequent process, the combination of an onset diabetes mellitus (DM) and diabetic ketoacidosis (DKA) is even rarer. DKA is one of the more serious known complications of the DM type 1 and type 2, which carries a rate of mortality between 2-5\% (3). Diverse circumstances (infectious diseases, omission or inadequate dose of insulin, alcohol consumption, surgical procedures, periods of long fasting or dietetic transgressions) can give place or accelerate the evolution of a DM (sometimes surreptitious) and determine its acute début as a DKA. Up to $20 \%$ of hospital admissions of patients due to DKA have a previous history of a DM not diagnosed before in the course of clinical situations as myocardium infarction, pancreatitis, pulmonary thromboembolism or infections (4), being infections of urinary tract and pneumonia the more frequently recognized. Though some cases of Ludwig's angina in diabetic patients have been reported, our work constitutes the first contribution to the medical literature of a Ludwig's angina in the context of a DKA combined to an onset DM.

\section{Case Report}

A 28-year-old man was referred for assessment of an infection originated in the left inferior third molar, which was resistant to an out-patient treatment, and showed worsening of his general condition, dehydration and severe trismus after a week of progress. He had been treated with amoxicillin/clavulanate $1 \mathrm{gr} / 62.5 \mathrm{mg}$ two capsules two times a day, deflazacort $30 \mathrm{mg}$ one tablet a day and paracetamol $1 \mathrm{~g}$ three tablets a day.

On physical exploration at his admission, the patient was agitated, disoriented, with taquipnea and sweaty. In addition he had temperature of $37.5^{\circ}$ and dysfagia to solid foods. He presented a diffuse swelling that was occupying the submental region and spreading to both jaw angles as well as to the parotid regions, with induration and painful tissues to the touch. In the intraoral examination the floor of the mouth was noticed tough, with selective painful percussion in the area of the third inferior left molar, though no fluctuating zone was found. The blood test showed a glycaemia of $678 \mathrm{mg} / \mathrm{dL}, \mathrm{pH}$ of 6.99 , bicarbonate of $2.5 \mathrm{mEq} / \mathrm{L}$, base excess of -27 , potassium of 4.9 $\mathrm{mmol} / \mathrm{L}$ and sodium of $130 \mathrm{mmol} / \mathrm{L}$, with a white cell count of 45.000 (93\% PMN). The patient weighted $125 \mathrm{~kg}$, heighted $171 \mathrm{~cm}$ and had a corporal index mass of 38.5. A radiographic examination by panoramic radiography and contrast-enhanced TC of face and neck was requested. Multiple gumboil and diffuse collections located in the bilateral supra-inframilohioid and submandibular spaces were shown, with free air among the muscular layers of the floor of the mouth (Fig. 1). The patient was diagnosed

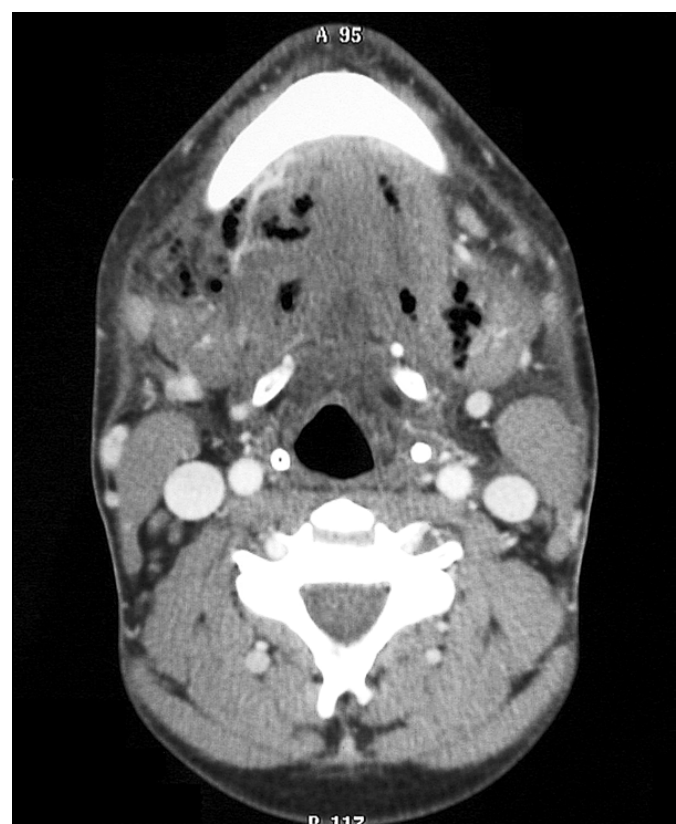

Fig. 1. Axial CT where gumboil collections appear at the supra-inframilohioid level and in the submandibular spaces, with free air among the muscular layers of the floor of the mouth. of severe DKA without DM's previously diagnosed in the context of Ludwig's angina of dental cause. An antibiotic intravenous treatment by combination of clyndamicin (600 mg/ every $8 \mathrm{~h})$ and tobramycin (100 mg/ every $12 \mathrm{~h}$ ) was prescribed; besides, the contribution of liquids was increased and intravenous insulin treatment was started. In view of the seriousness of the clinical symptoms he was admitted to the ICU. At 48 hours, under general anaesthesia after fiberoptic nasotracheal intubation, the patient was surgically operated; the third molar was removed as the source responsible of the infection, and a extraoral drainage was made by means of multiple incisions in the submandibular and submental region, obtaining abundant purulent material. Microbiological cultures were taken that turned out to be positive for Streptococcus constellatus. In the hemocultives Pseudomonas aeruginosa and Streptococcus mitis were isolated. By the $4^{\circ}$ day the patient began with a treatment according to the antiobiogram test with piperacilin-tazobactam 4gr intravenous every 6 hours and ciprofloxacine $400 \mathrm{mg}$ intravenous every 12 hours, which was prolonged for 10 days. The glucaemic and metabolic controls were gradually improving in relation to the reduction of the corticoid treatment and the resolution of the infectious clinical symptoms. The patient was extubated by the $6^{\circ}$ day and was sent to the hospitalization floor by the $8^{\circ}$ day. The cervical drainages were removed on the $12^{\circ}$ day (Fig. 2) and the patient was discharged by the $16^{\circ}$ day. He has been followed 


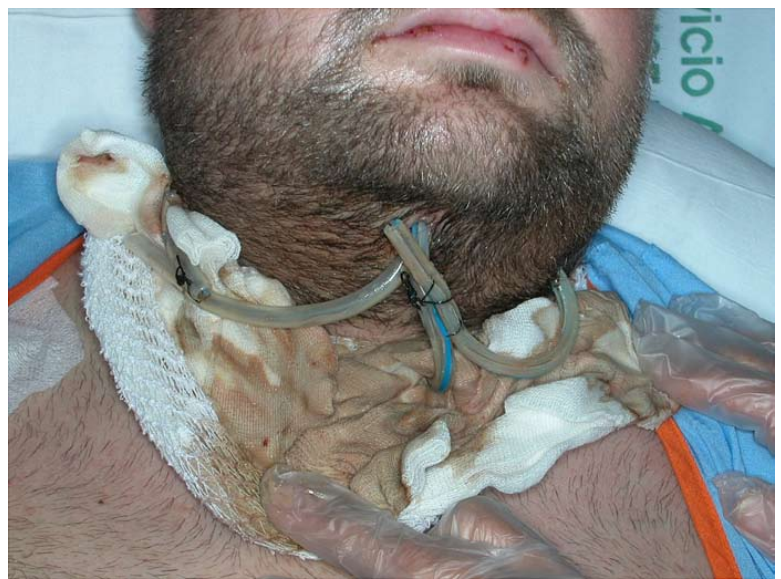

Fig. 2. Detail of a moment of the drainages cures making the suppuration evident.

up in the Endocrinology Department as outpatient, and a good glucaemic control has been achieved by means of a multidose insulinic therapy. A peptide $\mathrm{C}$ of 3.73 and $3.49 \mathrm{ng} / \mathrm{dL}$ (normal of 1.10-4.40 ng/mL), HbAlc initial of $12.2 \%$ and current of $7.8 \%$ (normal of $4-6 \%$ ) and antibodies antiGAD, antiIA2 and antiinsulin normal or negative $(1.21 \mathrm{U} / \mathrm{L}, 3.85 \mathrm{U} / \mathrm{L}, 2.32 \mathrm{U} / \mathrm{mL})$ were detected in the blood test, information that orientate us to the diagnosis of DM's type 2 with pancreatic islets reserve.

\section{Discussion}

Ludwig's angina usually has a dental origin, generally starting from an inferior molar caries infection (70$90 \%)(5)$. Other causes have been also described as infections of pharyngeal or tonsilar origin, infections for a foreign body or secondary infections to squamous cell carcinoma of the base of the tongue and the floor of mouth. One third of cases have been related to systemic illness like chronic glomerulonephritis, systemic lupus erythematosus, aplastic anemia, neutropenia, compromised immune system diseases (HIV+, AIDS) and DM (6). Streptococcus beta-hemolítico, staphylococci, and anaerobes as Peptostreptococcus and pigmented Bacteroides have been isolated as causal microorganisms (7). Also Escherichia coli and Borrelia vincentii have been involved.

It is characterized by an important muscular necrosis, though in the beginning a tendency to suppuration is not noticed, and when it appears, it does too late; in addition, this phenomenon takes place in a rapid form and without respecting any anatomical barrier. Its early recognition is crucial. The affectation of the overall condition is evident, since it curses with cervical pain, dysfhagia, dyspnea and fever. Locally, manifestations are relatively slightly striking. A bilateral suprahioid swelling appears, of hard consistency, not fluctuating and painful to touch. The mouth is half-opened and the tongue in contact with the palate, with marked oedema of the floor of the mouth. The presence of stridor, trismus, cyanosis and displacement of the tongue indicate an imminent compromise of the airway. The possible serious complications include sepsis, pneumonia, asphyxia, empyema, pericarditis, mediastinitis, and pneumothorax (8).

In poorly controlled diabetic patients infections can represent an important factor of co-morbidity. It is wellknown that these patients are inclined to the bacterial infections due to the weakening of the immunological system caused by the constant hyperglycemia and the bad chronic control (9). But during the infection, an increase of the endogenous production of glucose and a major resistance to the effect of the insulin are additionally produced, which can represent precipitant factors of the DKA. In our case report, the initial treatment with corticoids as an out-patient regimen could determine an increase of lipolysis and develop ketoacidosis in a state of relative insulin deficit and of major insulin resistance. The inappropriate use of corticoids could modify the clinical presentation of the odontogenic infection, provoking the development of complications.

The first therapeutic consideration in patients with Ludwig's angina is the airway management, because it is mandatory to preserve it early by means of a fiberoptic nasotracheal intubation or tracheostomy. In our patient, intubation monitorized by means of fiberoptic was an appropriate procedure since we avoid the tracheotomy due to the potential risk of spreading the infection to lower respiratory spaces. Different antimicrobial regimen have been recommended to cover in broad-spectrum the polymicrobial aetiology (gram - positives, gram-negatives, aerobes and anaerobes). Antibiotics used before obtaining the culture and the antibiogram results, have been penicillin $\mathrm{G}$ intravenous, clindamycin or metronidazole (10). Aminoglucosid have been also associated in some studies (5). Other alternatives described are ticarcilin, sulbactam-ampicilin or piperacilin-tazobactam. Cervical incision and surgical débridement are indicated in patients at risk of imminent complications or without improvement after 24 at 48 hours of intravenous antibiotics. The delay in the realization of the surgical intervention has been related to mortality increase (10). Our patient was taken to the operating room in the first 48 hours after the diagnosis establishment and admission to ICU. It has been demonstrated that early elimination of the dental focus of the infection reduces the time of recovery (1).

To sump up, Ludwig's angina is a potentially lethal infection. Airway obstruction and spreading of the infection towards the mediastinum are the most challenging complications, that is the reason why the maintenance of a safe airway and the early aggressive treatment, as was carried out in our case report, are crucial. Patients with factors of co-morbidity like the DM and with den- 
tal focus of infection need a special consideration like our patient, because they can break out eventually to serious medical complications as DKA and develop to potentially lethal cervical infections.

\section{References}

1. Boscolo-Rizzo P, Da Mosto MC. Submandibular space infection: a potentially lethal infection. Int J Infect Dis. 2009;13:327-33.

2. Britt JC, Josephson GD, Gross CW. Ludwig's angina in the pediatric population: report of a case and review of the literature. Int $J$ Pediatr Otorhinolaryngol. 2000;52:79-87.

3. Delaney MF, Zisman A, Kettyle WM. Diabetic ketoacidosis and hyperglycemic hyperosmolar nonketotic syndrome. Endocrinol Metab Clin North Am. 2000;29:683-705.

4. Shahgoli S, Shapiro R, Best JA. A dentoalveolar abscess in a pediatric patient with ketoacidosis caused by occult diabetes mellitus: a case report. Oral Surg Oral Med Oral Pathol Oral Radiol Endod. 1999;88:164-6.

5. Ho MP, Tsai KC, Yen SL, Lu CL, Chen CH. A rare cause of Ludwig's angina by Morganella morganii. J Infect. 2006;53:e191-4.

6. Chou YK, Lee CY, Chao HH. An upper airway obstruction emergency: Ludwig angina. Pediatr Emerg Care. 2007;23:892-6.

7. Jiménez Y, Bagán JV, Murillo J, Poveda R. Odontogenic infections. Complications. Systemic manifestations. Med Oral Patol Oral Cir Bucal. 2004;9 Suppl:143-7; 139-43.

8. Larawin V, Naipao J, Dubey SP. Head and neck space infections. Otolaryngol Head Neck Surg. 2006;135:889-93.

9. Chen MK, Wen YS, Chang CC, Lee HS, Huang MT, Hsiao HC. Deep neck infections in diabetic patients. Am J Otolaryngol. 2000;21:169-73.

10. Bross-Soriano D, Arrieta-Gómez JR, Prado-Calleros H, Schimelmitz-Idi J, Jorba-Basave S. Management of Ludwig's angina with small neck incisions: 18 years experience. Otolaryngol Head Neck Surg. 2004;130:712-7. 